\title{
THE RESEARCH OF METHODOLOGICAL WAYS FOR INCREASING THE EFFICIENCY OF USE OF THE INNOVATIVE POTENTIAL OF REGIONAL SOCIAL AND ECONOMIC SYSTEMS
}

\author{
Dmytro Solokha' ${ }^{1}$, Mariia Kovalova ${ }^{2}$ \\ Kyiv National University of Culture and Arts, Ukraine
}

\begin{abstract}
Modern conditions of the economic development based on market principles require significant changes in the system of economic governance both at national and regional levels, including in the management of inter-industry complexes, one of the most effective tools of which is the state governance. Investment and innovation policy is one of the most influential government economic methods of management of backbone enterprises in the region. The aim of state investment and innovation policy is primarily the creation of competitive environment and provision of structural changes and economic growth by improving the investment climate in the country, the development and intensification of the investment process, targeting investments in the priority sectors and programs. The importance of innovation potential in the socio-economic development of the country and regions is due primarily to the fact that the current conditions of industrial development and, as a result, the state's and region's economy, need a manufacturing application of innovative technologies as an indispensable condition to improve the competitiveness of the country and inter-industry complexes, among others. Providing the implementation of innovative technologies in production processes is one of the main duties of the state in the implementation of innovation policy. Thus, public authorities, both at national and regional levels, should create conditions for incentives of innovative activity, facilitating the rapid implementation of innovations in the production of specific products. The success of such processes is possible only by joint industrial, commercial, and banking capital into structures that are able to produce high-tech products, such as technopolis, technology parks, technological clusters, etc. Investments are the material basis of innovative processes. Activisation of investment activity, increased investments from all sources, and their effective use in innovation activities is a prerequisite for the sustainable economic development of Ukraine. The multidisciplinary nature of the economy indicates the need to use the relative interchangeability of the main types of productive resources in order to manage them most effectively within the enterprise, industry, and region. The quantitative measure of interchangeability of resources can be determined by establishing the functional dependence of their influence on the efficiency of production. Mathematical apparatus for the translation of multi-dimensional quantities in a comparable view is developed on the basis of existing modifications of production functions. It is determined that effective management of the development of the innovative potential of regional SES is carried out with the help of information support, which helps to obtain the synergy effect taking into account the following features: the complexity of the use of resources; complementarity of resources; interchangeability of resources. In connection with this, an interchangeability of resources has been proposed, which allows determining the variants of potential levels in the production of a certain volume of production in order to manoeuvre the resources in regional SES, which will ensure effective management of potential in general and innovative potential in particular.
\end{abstract}

Key words: efficiency, development, potential, region, socio-economic system, management, innovation, investment.

JEL Classification: B40, B55, C01, D26, H00, L38, L51

\footnotetext{
Corresponding author:

${ }^{1}$ Department of Economics, Kyiv National University of Culture and Arts.

E-mail: tttt66t@ukr.net

${ }^{2}$ Department of Economics, Kyiv National University of Culture and Arts.

E-mail: kovalova1503@gmail.com
} 


\section{Introduction}

The successful development of the country's economy depends largely on the successful development of its individual regions, whose development, in turn, depends on the system of economic governance both at the national and regional levels, which in turn is provided with the available potential and efficiency of its use.

The system of economic governance is a set of interrelated and coordinated means and methods of economic management that are used by state and regional governments and by appropriate management apparatus (Economic encyclopedia, 2000), but the current state of development of the economic system of Ukraine requires the search for fundamentally new approaches to the methodological bases for increasing the efficiency of using the potential of socioeconomic systems at the regional level as the basic component of the national economy, therefore, the topic of this work is timely and relevant.

The purpose of this work is to investigate methodological approaches to ensure and increase the effectiveness of using the potential of socioeconomic systems at the regional level in order to determine the most probable for the national economic system of Ukraine.

The methodological basis of the research that was conducted is scientific works on the identified issues of both domestic and foreign scientists, in particular (Economic encyclopedia, 2000; Matrosova, 2009; Solokha, 2011).

This research was conducted within the framework of research work of the Department of Economics of the Kyiv National University of Culture and Arts on the topic: Reasons for imperatives of innovative providing of the region.

\section{Characteristics of the system of state development management.}

Many researchers of the present day (Balabanov, 2000; Goncharov, 2009; Denysenko, 2008; Zaharchenko, 2012; Kovalova, 2014; Solokha, 2007) devoted their research to the problems of providing effective system management for the development of socioeconomic systems in the long run, however, due to its multidirectional and versatile nature, it remains still not fully resolved.

L.I. Skibitska emphasizes that system of management is a form of real implementation of management relationships, and administrative activity, in turn, represents management system functioning. S.V. Kivalov notes that management is a purposeful influence of the complicated system; the thoughts of these scientists are reflected in the work (Kovalova, 2014). In support of this idea, in the monograph (Kovalova, 2014) provides a well-known expression a famous saying the classic of management A. Fayolle from his work "General and industrial management". He characterizes management as follows: "To manage - means to lead the organization to its goal, extracting the maximum opportunities from all its available resources."

In our opinion, the enterprise management system should be understood as a set of purposeful, coordinated, interrelated, and complementary management actions concerning the company in order to achieve the highest possible economic result of their management, which will lead to the effectiveness of management at the regional and national levels.

Coordination of regional and state authority's actions concerning the management of the development of system creating enterprises of the region is a necessary condition for their successful and effective development, the result of which should be increase output volumes and the competitiveness level both finished products and regions and accordingly the state at the global level (Kovalova, 2014).

Modern conditions of the economic development based on market principles require significant changes in the system of economic governance both at national and regional levels, including in the management of interindustry complexes, one of the most effective tools of which is the state governance. O.P. Kopylenko, as noted by the author (Kovalova, 2014), gives the following definition of the state governance: "This is subordinate, legally and power, organizing activity of specific subjects, which consists in practical implementation of laws in the daily management of the economy, socio-cultural, administrative, and political development." According to O.Y. Vysotsky, O.E. Vysotsky, O.P. Sharov, the state governance is one of the kinds of state activity for the implementation of management organizing influence by using powers of executive authority through organization of implementation of laws, implementation of management functions for the purpose of complex socio-economic and cultural development of the state and its individual territories, and implementation of national policy in relevant spheres of social life, creation conditions for the realization by citizens of their rights and freedoms, proved in the monograph (Kovalova, 2014).

V.B. Averyanov distinguishes broad and narrow interpretation of the term "state governance". In his opinion, a broad interpretation of the state governance as the totality of all activities of the state (i.e., all forms of implementation of state power as a whole) is legitimate at the level of analysis in general the system of social (public) administration, the selection its relatively independent subsystems, proved by the author (Kovalova, 2014).

It should be noted that, at the same time, public and private structures are separate that have a different degree of management influence on society. In a narrow sense, the state governance is meant as a special and 
independent kind of activity of the state, carried out by a separate system of specialized government agencies and individual public authorities, including regional. Namely, as the author emphasizes, the state governance is an activity of a special kind, the content of which is to implement laws and other acts of state power through different forms of organizing influence on social phenomena and processes.

So, the state governance characterized by a deliberate action on the corresponding object of management, in this case, interbranch complex, moreover in a broad sense, the impact can be performed by both public authorities and non-governmental organizations that have this authority.

The impact on management object occurs through a number of methods determined by the leading scientists and is revealed in the monograph (Kovalova, 2014). S.M. Alferov, S.V. Vashenko, M.M. Dolgopolova, A.P. Kupin distinguish the following methods of the state governance:

1. Persuasion - campaigning, explanation, education, and so on.

2. Administrative, the essence of which is the adoption of administrative decisions, failure to comply of which by the object of control can cause a specific, according to law, administrative liability.

3. Economic - the creation of such economic conditions, in which the object of management implements tasks most effectively. These include: credit policy, price regulation, competition policy, transfers, and so on.

4. Compulsion - formation of the behaviour of control object against its will, while the control subject can forcibly affect the moral, financial, organizational, physical, psychological scope of control object with the aim of regulation.

5. Psychological - regulation of human relations.

Not all of the scientists distinguish separately psychological methods of state governance. In particular, the classification proposed does not contain them. In our opinion, this is due primarily to the fact that psychological management methods are more effective at the enterprise level, so in state government uses a combination of the first four management methods.

\section{The system of development management on a branch basis}

There are such types of the state governance: sectoral and intersectoral governance. L.G. Shmorgun determines sectoral governance as "a type of state management activity, which consists in the management of the similar enterprises' system from the authorized central body of executive authority that manages these companies, which create a branch in a social and economic complex of the state". V.K. Kolpakov and O.V. Kuzmenko are giving the same definition of the sectoral governance, investigated (Kovalova, 2014). Y.P. Bytyak notes that the essence of sectoral management consists in the organization of the effective functioning of sub-systems. Accordingly, the intersectoral governance consists in the state administrative activities of interbranch complexes development.

Sectoral management is carried out by the relevant ministries at the state level and by the regional authorities at the regional levels.

An important feature of sectoral management is a vertical relationship between subject and object of management. In this case, the governing bodies are the subject of management and objects are their managing objects.

Sectoral governance has a direct relationship of subordination. In its activity, sectoral governance bodies are governed by the relevant regulatory and legislative documents relating both directly to the specific industry and public administration in general. The competence of such governing bodies includes strategy development of a particular industry development and intersectoral systems and creating appropriate conditions for its implementation.

Sectoral management objects, in this case, are the entities of the industry, and the form of ownership does not matter. Also, sectoral and intersectoral objects of management can be different structural units of a particular industry (economic, cultural, medical) in certain administrative and territorial units, subordinated to relevant ministries. Thus, the essence of sectoral governance consists in system organization of the effective functioning of the industry and the aggregate of all forms of management activities of the authorities that are competent in such management.

The sectoral management system is formed within the specific economic sectors and within definite legal provisions, which are determined by special regulations for each branch.

Based on the foregoing, we can conclude the following: sectoral governance is defined as the authorized state bodies' management within their competence with respect to several business sectors. Note that in this case, intersectoral management body has certain powers, including governmental, for those companies or institutions that it can't subordinate organizationally. So, the main function of sectoral governance is the organization of effective functioning of inter-industry complexes and coordinated actions of all enterprises included in its composition.

Based on the foregoing can be singled out the following functions of intersectoral authorities:

- definition and rationale of directions of intersectoral complexes;

- ensuring appropriate normative and legal support for the activities of interbranch complexes;

- solution of interbranch complex problems considering the national and regional interests. 
Intersectoral governance, unlike sectoral, is characterized by horizontal relationship, i.e. subjects and objects of this type of management are not subordinated organizationally. Intersectoral executive and administrative activities lay mainly on state committees, services, administration, and inspection of Ukraine, in some cases to ministries. These authorities carry out interdepartmental coordination on issues within their competence and functional regulation in a specific area of activity. The main purpose of interbranch management is to ensure coordinated functioning and development of all sectors and parts of the socio-economic complex through the constant and purposeful work to resolve inter-ministerial problems.

The field of activity of intersectoral authorities is broader than the field of sectoral management because their activity is distributed into several branches at once. It should be noted that boundaries of the field of activity of intersectoral authorities are constantly expanding that is explained first of all by that modern conditions of economic development require coordinated actions of sectoral bodies and overall coordination. As a result, entities of management of intersectoral complexes are endowed with the regulatory and coordinating functions.

So, sectoral governance gradually fades into the background, giving way to intersectoral governance. The regulatory functions of interbranch management acquire relevance too. Thus, the essence of government regulation is to guarantee coordinated actions of all administrative bodies and the interbranch government is to coordinate the actions of enterprises, institutions, and organizations irrespective of their subordination. Such a coordination turns out (or intersectoral management) in the implementation by the competent authorities of one or more functions of the state in all sectors.

Investment and innovation policy is one of the most influential government economic methods of management of backbone enterprises in the region.

The aim of state investment and innovation policy is primarily the creation of competitive environment and provision of structural changes and economic growth by improving the investment climate in the country, the development and intensification of the investment process, targeting investments in the priority sectors and programs (Zaharchenko, 2012).

\section{Investment fundamentals of innovation potential management}

Innovation potential management is one of the decisive factors of development, and therefore, an important part of the management of inter-industry complexes. V.I. Zakharchenko defines innovation potential as one of the three components of the innovation space, which includes personal and business qualities of managers, professional and economic training, professional achievements, logistical and financial support, etc. (Zaharchenko, 2012; Zaharchenko, 2004).

I.T. Balabanov gives the following definition of innovation potential: “... a combination of different resources, including physical, financial, intellectual, information and other resources that are necessary for the implementation of innovation" (Balabanov, 2000).

The importance of innovation potential in the socioeconomic development of the country and regions is due primarily to the fact that the current conditions of industrial development and, as a result, the state's and region's economy, need a manufacturing application of innovative technologies as an indispensable condition to improve the competitiveness of the country and interindustry complexes, among others. S. Ischuk's works that are analysed in the monograph (Kovalova, 2014) prove that the leading innovations in the industry are:

1) the creation of new equipment and new substances and materials, which help to reduce the production costs, improve quality, reduce the cost of natural, human, and financial resources, reorganization and modernization of industrial enterprises;

2) attracting investments in the development of new technologies;

3) improving the innovation systems by optimizing the production cycle using innovative approaches.

The successful implementation of the abovementioned trends is possible only if innovative and accordingly the scientific potential of individual regions and the country as a whole will develop. So, scientific and innovation potential concerning the development of certain interbranch complex defines:

1) the degree of implementation of innovations in production - reducing the number of morally and physically obsolete equipment, the use of low-waste, energy-saving technologies;

2) the development of high-tech activities;

3) a compliance with international standards of the technical and technological base of the interbranch complex;

4) improving the labour productivity and, as a result, the profitability of production;

5 ) growth rates of capital-labour ratio and capital productivity;

6) increasing the share of inter-industry complexes in the export of the country and achieving a high-level competitiveness in the global market.

The outcome of scientific and innovation potential action on the functioning of the inter-branch complex should be:

the improvement of technical and technological parameters of both large and small enterprises of the interbranch complex;

increasing role of inter-industry complexes that are actively used in the manufacture innovation and form the so-called "innovation economics framework"; 
changes in the competition nature - development of new technologies and services is at the forefront;

predictability of innovations market;

growth in the interdependence of the national economy and intersectoral systems;

creation of a new type of enterprise that requires minor raw materials and human resources, however, due to an innovative vector of its activities has the high rates of profit and profitability.

Having a direct impact on the national economy and its individual regions, scientific and innovation potential may have a different impact on the development of separate inter-industry complexes. This is explained by varying degrees of industries willingness to accept the innovative technologies because of the uneven development of the industry.

Emphasize on the impossibility of successful innovation activity without systematic and consistent public administration, whose functions include the creation of the legal framework, the choice of priorities of innovation activity, financial support, the establishment of appropriate infrastructure.

Providing the implementation of innovative technologies in production processes is one of the main duties of the state in the implementation of innovation policy. Thus, public authorities, both at national and regional levels, should create conditions for incentives of innovative activity, facilitating the rapid implementation of innovations in the production of specific products. The success of such processes is possible only by joint industrial, commercial, and banking capital into structures that are able to produce the high-tech products, such as technopolis, technology parks, technological clusters, etc. (Kovalova, 2014).

Investments are the material basis of innovative processes. Activisation of investment activity, increased investments from all sources, and their effective use in innovation activities is a prerequisite for the sustainable economic development of Ukraine. A.F. Melnyk notes that the state investment policy for the development of inter-industry complexes, as noted in the work (Kovalova, 2014), provides the following:

creating a favourable investment climate through the development of a system of long-term investment credit;

introduction of economic mechanisms for attracting investments in the competitive industries;

directing the public investment resources purely on the development of priority sectors;

optimization of amortization policy;

implementation of tax policy that encourages the investment and innovation activity;

improving the economic, legal, and institutional investors operating conditions;

development of insurance business;

strengthening the role of institutional investors (pension funds, investment funds, and insurance funds); creating a sovereign investment fund of industry; implementation of the joint (government and business) large-scale investment projects.

Foreign experience demonstrates the success of the so-called coordination management system, which provides coordination between all participants of investment activity in the region (Kovalova, 2014; Solokha, 2011). The functional responsibilities of relevant government authorities also include the development of actions on the implementation of investment and innovation policy. That includes:

implementation of statutory and legal regulations and proper support for contractual relationships with regional authorities or agencies who have certain powers;

providing appropriate conditions for the effective cooperation between financial institutions and manufacturing companies by providing preferential loans, reducing utility tariffs etc.

identifying forms of local authorities' responsibility for implementing measures within the investment policy and the possible negative consequences (violation of an environmental protection, land planning zone, etc.);

providing communication with the public through the media to the general demonstration of realized investment policy in the region in order to attract public organizations and the public to participate in deciding on the advisability and directions of its further development.

Overseas the investment policy in the region is a factor of stabilization of the economy, where the number and depth of the economic and social problems are so great that need its own solution that the only possible way to achieve goals that set by reforms is gradual and systematic movement towards building a new investment mechanism in the development of market relations.

The investment is one of the most important instruments of state policy in the sphere of the economy. World experience shows that one of the main factors that determine the need to attract investments is the lack of national financial resources for the development of a particular sector, the result of which is the reduction of production. One of the main problems that arise in the implementation of public investment policy, there is lack of coordination between public authorities at regional and national levels (Solokha, 2011).

One of the main tasks of authorities at the regional level is the assistance for companies that are interested in investing their money in the economy of a particular region. However, the investment process at the regional level has certain features that are mainly associated with specific sources of investment and limited stage of reproduction that occur in regional structures.

Foreign experience demonstrates the effectiveness of such instruments for attracting investments as tax credits, reduced rates for transport and energy, preferential 
loans and so on. Planning and creating separate objects of social value, as well as the development of small urban and rural settlements, is now the prerogative of local government, the object of work during formation of investment policy in the region. It should be noted that in these cases, a mechanism of the public and private partnership is widely used. Special plots are provided by the regional authorities that ultimately contribute to solving the urgent tasks of areas' development by construction and reconstruction, upgrading existing infrastructure in the region.

So in the process of development of backbone enterprises at the regional level, for their successful development, it is important to use the totality of management practices at the state level too. It is necessary to emphasize the importance of investment and innovation policy, the successful implementation of which is possible only by joint efforts of state authorities at all levels and representatives of companies belonging to the interbranch complex. Sustainable economic development of the regions and country as a whole and thus increase in the level of the country's competitiveness globally is possible only on condition of the effective management system of interbranch development at the regional level.

\section{Investigation of the management system of the resource potential of innovations}

First of all, development of regional SES is determined by the application of progressive forms of management that provide effective potential management in accordance with the specific needs of production.

Various statistical information is required for the effective management, which reflects all the peculiarities of the development of the potential of the SES of the regional level.

Improving the quality of management of SES potential is the main condition for the quality functioning of the system and the achievement of a synergistic effect.

The effectiveness of the synergistic effect depends on the structure and reliability of the information. In the case of unbelievable information, potential development will lead to a variety of conflicting management requirements, which will result in inefficient use of SES resources and put at risk the outcome.

In addition to the synergistic effect, information resources provide reliability of the functioning of the potential of regional SES and its flexibility relative to the environment.

Thus, efficient management of the innovative potential of the SES at the regional level is carried out with the help of information support, which helps to obtain the synergy effect, taking into account the following features: the complexity of the use of resources; complementarity of resources; interchangeability of resources.
The concept of the complexity of the use of resources means multipurpose processing and ensures maximum use of their consumer properties, providing diverse technological processes with raw materials. The property of complexity is especially relevant in the conditions of modern requirements for production when on the agenda was the task of transition to an innovative model of management and implementation of resource-saving technologies. For example, increasing the complexity of using resources makes it possible to relatively reduce the amount of ore extraction by increasing the depth of processing and extraction of related utility elements.

Complementarity of resources is expressed in the necessity of observing certain volumetric proportions of specific types of resources with the given production technology and the current type of consumption.

The most characteristic complementarity for productive material resources, but it also manifests itself in the structure of the workforce, which can affect the shortage of workers of a certain qualification and specialty.

Interchangeability of resources is related to their multifunctionality and assumes the possibility of replacing one resource with another in the technological process, practically without affecting the volume and quality of the final product, that is, the same resource can be used for the satisfaction of different functional needs, and each need can be provided with different sets of resources.

Each new type of combination of potential components modifies the old one and causes the new content of the form of interchangeability.

Existing limitations of the SES resources are not an insurmountable obstacle to implementing the principle of their interchangeability. Rather, the possibility of replacing resources expands the boundaries of further development of the potential of the socio-economic system. It is noted that the limitation of resources at the moment do not contradict the objective possibility of their increase in the future or the expansion of interchangeability of resources in meeting those or other needs (Goncharov, 2009; Zaharchenko, 2012; Kovaleva, 2014; Matrosova, 2009; Solokha, 2011).

In our opinion, the solution to the problem should be sought in a skilful combination of cost and natural indicators of evaluation, creating a reliable mechanism of influence at the SES regional level in order to increase the efficiency of the use of production resources.

The multidisciplinary nature of the economy indicates the need to use the relative interchangeability of the main types of productive resources in order to manage them most effectively within the enterprise, industry, and region.

The quantitative measure of interchangeability of resources can be determined by establishing the functional dependence of their influence on the efficiency of production. Mathematical apparatus for 
the translation of multi-dimensional quantities in a comparable view is developed on the basis of existing modifications of production functions.

The estimation of interchangeability of resources is carried out using a system of indicators, each of which has a double positive load in analytical comparisons. While indicators with the stand-alone mode of operation contain features that reflect the essence of a particular problem, from the positions of complex analysis they are simultaneously subordinate and applicable to determine the level of comparability of SES resources. The duality of the load inherent in this system of indicators is to use functional properties of the potential both for the selfassessment of the determined and for the quantification of the substitution of resources.

\section{Modelling of the control system of the potential of the SES of the region}

The principle of interchangeability of the components of the aggregate potential of SES involves the ability to achieve a balanced equilibrium of potentials for resource sources $\left(x_{i}\right)$ (Solokha, 2011). The principle of interchangeability of the components of the aggregate potential of SES involves the ability to achieve a balanced equilibrium of potential for resource sources $\left(x_{i}\right)$ (Solokha, 2011). This means that with growth, for example $x_{1}$, by reducing $x_{2}$, interchangeability will be optimal in the case when the production process uses more efficient ones.

Another feature of interchangeability $x_{i}$ is inductance, which is manifested in the fact that the replacement of one element in many cases creates the possibility for a number of other substitutions, or even makes them necessary. The determination of the interchangeability of potentials by resource sources is based on the ideas of boundary analysis.

Consider the production function $y=f\left(x_{1}, x_{2}\right)$, where $-y$ the volume of production of SES, which in some way depends on the potential for two sources of resources $x_{1}$ and $x_{2}$. (Denysenko, 2008).

This approach allows, on the one hand, constructing the curves of the interchangeability of potentials by resource sources, and on the other hand, organizing and ranking the levels of use $x_{i}$ for their advantage in terms of maximizing production volumes.

Partial derivative functions $\mathrm{f}$ on $x_{i}$ are called the marginal profitability of potentials by resource sources and determined by:

$$
\begin{aligned}
& f_{1}=\frac{\partial f}{\partial x_{1}} \\
& f_{2}=\frac{\partial f}{\partial x_{2}}
\end{aligned}
$$

At the same time, the direct quantitative description of proportions of the replacement of a limited volume of potentials gives the marginal rate of their substitution:

$$
q=\frac{\partial x_{2}}{\partial x_{1}}=\frac{f_{1}}{f_{2}} .
$$

In many practical cases, the productivity of differently effective potentials, drawn in a consistent manner in the production process for its additional release, decreases. In this regard, there is a tendency to increase the marginal rate of interchange, which means that with the growth of the level of one resource source $x_{1}$ compared with the $x_{2}$ replacement of a unit $x_{2}$ requires a larger size of $x_{1}$.

The production of products with the presence of interchangeable potentials for resource sources is characterized by a function that models production as a surplus of degrees of spending resources of the i kind in the volume $x_{i}$ :

$$
y=A \prod x_{i}^{a_{i}},
$$

where $A$ and $a_{i}$ - function parameters.

In ensuring the production of products requires the mandatory participation of the totality of $x_{i}$, that is $y>0$, will only in the case if $x_{i}>0$ for all $i=1.2 \ldots \ldots$

Thus if $\sum_{i=1}^{n} a_{i}<1$ then $y$ characterized as decaying efficiency of production with increasing the level of use of $\mathrm{x}$ i, but if $\sum_{i=1}^{n} a_{i}=1$ then the efficiency remains constant, and $\sum_{i=1}^{n} a_{i}>1$ corresponds to increasing efficiency of successive costs.

The production of products is often characterized by the impossibility of replacing of $x_{1}$ with $x_{2}$ through the valuation of resources, legal restrictions, etc. For example, in excess of the fleet of cars and the shortage of worker-drivers, there is no possibility of replacing a part of the machines with the corresponding wage fund and material incentives. Therefore, production is carried out in two ways: zero replacement elasticity of $x_{i}$; with non-zero replacement elasticity of $x_{i}$.

Provided the zero replacement elasticity of $x_{i}$ let the production is determined by the potential of the SES in accordance with the production function of the type "cost-issue", so if the potential of the SES is defined as $\bar{x}=\left(x_{1}, \ldots, x_{n}\right)$ then can be produced $y=\min \left[\frac{x_{1}}{a_{1}}, \ldots, \frac{x_{n}}{a_{n}}\right]$ units of products.

If the volume of production can only be discrete, then $y=\min \left[E \frac{x_{1}}{a_{1}}, \ldots, E \frac{x_{n}}{a_{n}}\right]$ where $E(x)$ - the whole part of $x$.

Determination of SES potential unit $(r)$, as a set of minimum quantities of individual potentials for resource sources, which allows getting a unit of production, in this case, is especially simple $r=\left(r_{1}, \ldots, r_{n}\right)=\left(a_{1}, \ldots, a_{n}\right)$. At the same time, $r$ corresponds to such many separate ones $x_{i}$, for which $\forall i=1, \ldots, n x_{i}=a_{i}$. If $\exists i$, that is $x_{i}>a_{i}$ and $\exists j$, that is $x_{i}=a_{i}$, then as before, only one unit of output will be produced, and the potential 
will not be isolated at the same time. In this case, it will contain an incomplete part that cannot be used directly to achieve the purpose of the system. And in the general case, with the impossibility of replacement, the potential SES R can always be represented, in the form:

$$
R=N r+\Delta R
$$

where $\mathrm{N}$ - number of units of SES potential;

$\Delta R$ - incomplete part of the potential of SES.

Investigate the situation when the production function of the system $f(\bar{x})$ is characterized by a nonzero elasticity of substitution and homogeneity of the first order. To illustrate, we use the Cobb-Douglas function and the production function with "constant elasticity of the substitution." In this case, each point of the surface $f\left(x_{1}, \ldots, x_{n}\right)=1$ is minimal in Pareto and, therefore, can be taken as a unit of SES potential.

To select any one point and to compare different sets of $x_{i}$, the additional criteria and restrictions must be used.

1. Often, technological constraints on the replacement of types of resources dictate the relation between the elements of the SES potential. These relations give us no limits to select a single point on the surface $f\left(x_{1}, \ldots, x_{n}\right)=1$.

Let the relationships look like this:

$$
x_{1} \div x_{2} \div \ldots \div x_{n}=k_{1} \div k_{2} \div \ldots \div k_{n} \text {, }
$$

where $k_{1}, k_{2}, \ldots, k_{n}$ - the indicated values.

Modify these relationships in the form of $(n-1)$ equations and attach to them the equation of the surface:

$$
\begin{aligned}
& \left\{\begin{array}{l}
x_{1}=x_{n} \frac{k_{1}}{k_{n}} \\
x_{2}=x_{n} \frac{k_{2}}{k_{n}} \\
\cdots \\
x_{n-1}=x_{n} \frac{k_{n-1}}{k_{n}} \\
f\left(x_{1}, \ldots, x_{n}\right)=1
\end{array}\right. \\
& \text { So, } f\left(x_{1} \frac{k_{1}}{k_{n}}, \ldots, x_{n-1} \frac{k_{n-1}}{k_{n}}, x_{n} \frac{k_{n}}{k_{n}}\right)=1
\end{aligned}
$$

Table 1

Determination of components of the unit potential of the SES

\begin{tabular}{|c|c|c|}
\hline Functions & Criteria and restrictions & Decision \\
\hline Cobb-Douglas function & $\forall i=1, \ldots, n$, & $x_{i}=r_{i}=\frac{\alpha_{i} / c_{i}}{f\left(\alpha_{1} / c_{1}, \ldots, \alpha_{n} / c_{n}\right)}$ \\
$f(\bar{x})=a_{0} \prod_{i=1}^{n} x_{i}^{a_{i}}$ & $\alpha_{i} \geq 1$ & \\
Function with "constant elasticity of replacement" & $\sum_{i=1}^{n} \alpha_{i}=1$ & $x_{i}=r_{i}=\frac{\left(A_{i} / c_{i}\right)^{\frac{1}{\alpha+1}}}{f\left(\left(A_{1} / c_{1}\right)^{\frac{1}{\alpha+1}}, \ldots,\left(A_{n} / c_{n}\right)^{\frac{1}{\alpha+1}}\right.}$ \\
$f\left(x_{1}, \ldots, x_{n}\right)=A_{0}^{\left(\sum_{i=1}^{n} A_{i} x_{i}^{-\alpha}\right)-\frac{1}{2}}$ & $A_{0} \geq 0$, & $i=1, \ldots, n$ \\
\hline
\end{tabular}


In turn, $f(\bar{r})=\frac{1}{N}, f(\bar{R})=1$.

In determining the number of units of socio-economic system potential, two cases are admissible:

1) The number of units can only be integral, and the production function involves the replacement. In this case, actually produced $E(N)$ units of production per unit of SES potential can be selected:

$$
\bar{r}=\frac{1}{k} \bar{R},
$$

where $\frac{N}{2}<k>N$.

In this case, $f(\bar{r})=\frac{1}{k}, f(\bar{R})=\frac{N}{k} \quad$, and $E\left(\frac{N}{k}\right)=1$, with mandatory condition $1 \leq \frac{N}{k}<2$. This suggests that the choice of any value of $k$ only one product unit will be produced.

2) Per unit of potential CEC $\bar{r}=\left(r_{1}, \ldots, r_{n}\right)$ selected single (for example, the least cost) set of potentials by the resource sources represented by the dot of the surface of a single issue.

Let us have a set of potentials for resource sources $\bar{R}=\left(R_{1}, \ldots, R_{n}\right)$, moreover, $f(\bar{R})=N$. Then the point $\frac{1}{N} \bar{R}$ will lie on the surface of a single issue and formally meet all the requirements for the unit of SES potential. If $\bar{c}=\left(c_{1}, \ldots, c_{n}\right)$ - the vector of prices of units of each type of potentials by resource sources, then from the optimality of the set $\bar{r}$ the solution of the problem is the existence of a vector $\bar{x}=\left(x_{1}, \ldots, x_{n}\right)$, which is the solution to the problem $f(\bar{x}) \rightarrow$ max provided $c_{1} x_{1}+\ldots+c_{n} x_{n}=\frac{1}{N}\left(c_{1} R_{1}+\ldots+c_{n} R_{n}\right)$ that it can be achieved release $f(\bar{x}) \triangleright 1$, if $\exists i$, that is $r_{i} \uparrow \frac{1}{N} R_{i}$. This means that at the same price can be acquired a set of potentials from resource sources, which provides a larger amount of output than the given set. The considered case shows that if the level of $\bar{R}=\left(R_{1}, \ldots, R_{n}\right)$ such that $f(\bar{R})=N$ and, in addition, $\exists i, r_{i}=\frac{1}{N} R_{i}$, then in the set $\bar{R}$ contains more than $N$ of SES potential units (optimal by value or by any other criterion).

Thus, the proposed approach of interchangeability of resources made it possible to determine the variants of potential levels in the production of a certain amount of production, in order to manoeuvre the resources in the SES, which will ensure effective management of the potential in general.

\section{Conclusions}

It is determined that the methodology of modelling the resource provision of efficient management of the innovative potential of the SES of the regional level is the methods of system analysis and forecasting, the possibility of representing all processes occurring in the industrial sphere as a subsystem of economic development. This became possible due to the improvement of the apparatus of economicmathematical modelling and its use in the modelling of complex SES.

It is proved that each SES in the course of its development can increase the production of the corresponding products in two ways - either by increasing the quantitative indicators of its potential (extensive way of development) or increasing the level of potential at the expense of qualitative indicators (an intensive way of development).

Existing general definitions of the level of development of SES cannot be used to control the development of systems since they only capture the actual state of their development.

In modern conditions, such a calculation model is needed that would allow determining the levels of development of the corresponding systems at any given time.

The proposed economic-mathematical toolkit, which will determine the significance of the development of the innovative potential of the SES at the regional level at any given time, which, in turn, can be used to increase the effectiveness of planning and management of the socio-economic development of the region.

It is determined that effective management of the development of the innovative potential of regional SES is carried out with the help of information support, which helps to obtain the synergy effect taking into account the following features: the complexity of the use of resources; complementarity of resources; interchangeability of resources.

In connection with this, an interchangeability of resources has been proposed, which allows determining the variants of potential levels in the production of a certain volume of production in order to manoeuvre the resources in regional SES, which will ensure effective management of potential, in general, and innovative potential, in particular.

Further research should focus primarily on the approbation of the proposed mathematical toolkit as a methodological basis for improving the management efficiency of the innovative potential of the SES of the region on specific statistical data and actual results of management.

Secondly, on the construction of an economics and mathematical multivariate model, with which one can assess the level of efficiency of the existing SES potential of the region at each specific moment of time, identify reserves and replace certain components of the resource potential in order to provide innovative development of the regions in the long-term perspective. 


\section{References:}

Balabanov, I.T. (2000). Innovation management. St.Petersburg. Russia: Piter [in Russian]

Butnyk, O.O. (2011). Foreign experience of formation and development the state investment policy at the regional level. Kyiv.Ukraine [in Ukrainian]

Goncharov, V.M., Derechynskiy, U.N. ... Bieliakova, O.V. (2009). Formation of organizational mechanism of the system of innovative development of enterprises of the region. Donetsk. Ukraine: Kupriianov [in Ukrainian].

Denysenko, M.P., Myhailova, L.I. ... Grechan, A.P. (2008). Investment and innovation activity: theory, practice, experience. Sumy. Ukraine: University book [in Ukrainian]

Economic encyclopedia. (2000). (Vols.1-3). Kyiv.Ukraine.

Zaharchenko, V.I. (2012). Innovation Management: theory and practice in conditions of economy transformation. Kyiv. Ukraine: Center for Educational Literature [in Ukrainian]

Zaharchenko, V.I. (2004). Transformation processes in industrial territorial systems of Ukraine. Vinnytsia. Ukraine: Gipanis [in Ukrainian]

Zang, V.B. (1999). Synergetic economy. Time and changes in nonlinear economic theory. Moscow. Russia: World [in Russian]

Kovalova, M.L. (2014). Territorial organization of the forest industry of Ukraine: regional aspect. Donetsk. Ukraine: Dmytrenko [in Ukrainian]

Kovalova, M.L. \& Batchenko, L.V. (2011). Furniture market in Ukraine and its interaction with the world market. Donetsk. Ukraine: DonSUM [in Ukrainian]

Matrosova, L.V., Ovechkina, O.A., Ivanova, K.V., Solokha, D.V. (2009). Management of the development of innovative potential of regions in the transitional economy of Ukraine. Donetsk. Ukraine: Donbass [in Ukrainian]

Solokha, D.V., Bandyra, M.V., Savchenko, M.V., Moreva, V.V.(2011). Methodological bases of management of sustainable innovation development of potential of socio-economic systems of the region. Donetsk. Ukraine: Noulidzh [in Ukrainian]

Solokha, D.V. (2007). Innovative development as a guarantee of economic growth. Donetsk. Ukraine [in Ukrainian] 